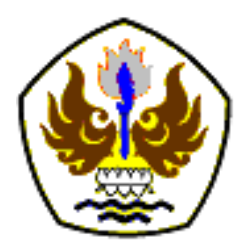

INFOMATEK

Volume 22 Nomor 2 Desember 2020

\title{
ANALISIS PENGARUH PEMASANGAN MUFFLER PADA MESIN PESAWAT TANPA AWAK LSU 02 TERHADAP TINGKAT KEBISINGAN
}

\author{
Evi Sofia*), Ilham Achmal Hakiki \\ Teknik Penerbangan \\ Fakultas Teknik- Universitas Nurtanio
}

\begin{abstract}
Abstrak: LSU-02 merupakan pesawat tanpa awak yang dikembangkan oleh Pustekbang LAPAN dan mulanya akan menggunakan mesin 3W28i. Namun karena mesin 3W-28i memiliki muffler yang panjang, maka dalam penelitian ini akan dilakukan modifikasi dengan memvariasikan panjang dan diameter muffler. Selanjutnya dilakukan simulasi untuk mengetahui pengurangan tingkat kebisingan yang dihasilkan. Proses simulasi menggunakan metode computational fluid dynamic (CFD) dengan menggunakan perangkat lunak ANSYS Harmonic Acoustic. Dari hasil simulasi diperoleh kesimpulan jika semakin besar diameter muffler $(80 \mathrm{~mm})$ memberi kontribusi yang lebih baik dalam mengurang tingkat kebisingan sebesar $21.587 \mathrm{~dB}$. Kemudian pengaruh panjang muffler terhadap pengurangan kebisingan tidak terlalu besar, karena selisih pengurangan kebisingan hanya sebesar $0,658 \mathrm{~dB}$. Sehingga disarankan untuk menggunakan muffler model 5 dengan diameter $80 \mathrm{~mm}$ dan panjang $130 \mathrm{~mm}$ untuk dipasangkan pada mesin $3 \mathrm{~W}-28 \mathrm{i}$ karena memiliki ukuran yang lebih kecil namun mampu mengurangi kebisingan hingga 20,929 dB.
\end{abstract}

Kata kunci: CFD, Kebisingan, Muffler, Pesawat Tanpa Awak

\section{PENDAHULUAN}

\subsection{Latar Belakang}

Pesawat tanpa awak merupakan sebuah pesawat terbang ringan yang dapat dikendalikan dari darat menggunakan remote control serta mampu terbang secara autonomous sesuai dengan way point yang diinginkan (Bintoro [1]). Salah satu pesawat tanpa awak tersebut adalah LSU-02 yang dikembangkan oleh Pustekbang LAPAN

\footnotetext{
*)e.sofia284@gmail.com
}

Pertama diterima: 29 Oktober 2020

Direvisi: 11 November 2020

Disetujui untuk publikasi: 12 November 2020 dengan konfigurasi high wing, twin tail boom, dan pusher engine. Mulanya, pesawat LSU-02 akan menggunakan mesin $3 \mathrm{~W}-28 \mathrm{i}$, namun mesin tersebut memiliki dimensi muffler yang terlalu panjang. Sehingga dikhawatirkan akan menimbulkan gaya hambat ketika dipasang pada pesawat LSU-02. Namun jika tidak dipasang muffler akan menimbulkan kebisingan yang cukup besar. Kebisingan merupakan suatu suara atau bunyi yang tidak diinginkan dari suatu kegiatan dalam tingkat dan rentang waktu tertentu sehingga dapat mengganggu secara fisik (indera pendengaran manusia) dan psikis (mengganggu konsentrasi 
dan kelancaran komunikasi) serta dapat menjadi polutan bagi lingkungan (KLHK [2]).

Beberapa kajian dilakukan untuk mengetahui pengaruh. Pengaruh panjang pada reduksi suara Muffler Jenis Ekspansi diinvestigasi oleh Sunil Khokhar dkk dengan metode eksperimen dan simulasi aliran pada tahun 2016 (Patel [3]).

Pada tahun 2017 Harahap dkk melakukan kajian untuk mereduksi kebisingan yang dilakukan pada pesawat tanpa awak NVC USU (Harahap [4]). Kajian dengan menggunakan CFD untuk memprediksi kebisingan knalpot pernah dilakukan oleh Liu dkk [5]. Kajian-kajian lain yang dilakukan untuk mengetahui tingkat kebisingan terhadap pesawat terbang dan nilai transmisson loss dilakukan oleh beberapa peneliti (Wu [6], Kore [7], Ji [8]).

Berdasarkan latar belakang tersebut, maka pada penelitian ini akan dilakukan modifikasi pada model muffler mesin 3W-28i dengan melakukan perbandingan diameter dan panjang muffler yang disesuaikan terhadap lebar fuselage pesawat LSU-02.

\section{METODOLOGI}

Proses simulasi menggunakan metode computational fluid dynamic (CFD) dengan perangkat lunak yang digunakan adalah ANSYS Harmonic Acoustic. Hasil dari simulasi nantinya akan dilihat pengaruh diameter muffler terhadap kemampuan dalam meredam kebisingan, pengaruh panjang muffler dalam meredam kebisingan, serta panjang dan diameter muffler yang disarankan untuk mesin 3W-28i.

\subsection{Spesifikasi Pesawat LSU-02}

Pesawat LSU-02 merupakan salah satu pesawat tanpa awak yang telah dikembangkan oleh Pusat Teknologi Penerbangan LAPAN. Pesawat ini termasuk dalam kategori pesawat ringan yang memiliki misi sebagai surveillance tactical. Dalam pengembangan desain dan konfigurasinya, pesawat LSU-02 terinspirasi dari Skyhunter UAS Family. Konfigurasi pada pesawat LSU-02 ditampilkan pada Gambar 1.

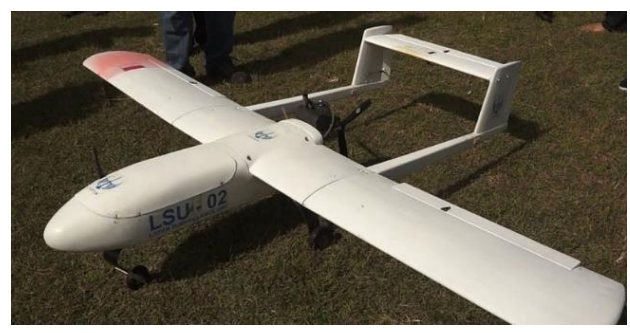

Gambar 1

Pesawat LSU-02

Mesin pesawat LSU-02 menggunakan mesin 3W-28i merupakan piston dua langkah satu silinder yang dikembangkan oleh perusahaan asal Jerman yaitu $3 W$ 
International . Model dari mesin 3W-28i dapat dilihat pada Gambar 2.

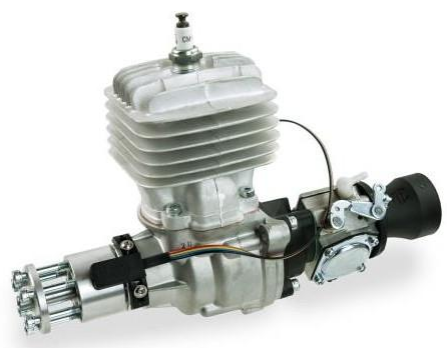

Gambar 2

Mesin 3W-28i

\subsection{Transmission Loss}

Salah satu parameter performa akustik dalam melakukan eksperimen atau simulasi pada suatu muffler adalah transmission loss. Transmission loss merupakan sifat dari muffler yang didefinisikan sebagai rasio logaritmis pada muffler berdasarkan perbedaan antara sound power yang masuk ke muffler dengan sound power yang keluar dari muffler, proses dari transmission loss diilustrasikan seperti pada Gambar 3 .

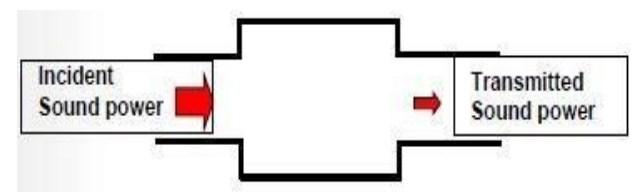

Gambar 3

Transmission loss

Transmission loss umumnya digunakan sebagai parameter dari kemampuan suatu bahan dalam meredam bunyi. Nilai dari transmission loss dapat dihitung menggunakan Persamaan 1 jika nilai dari sound power yang masuk dan keluar dari muffler telah diketahui. Namun jika kedua nilai tersebut tidak diketahui, maka nilai transmission loss dihitung menggunakan Persamaan 2 (Milad [9], Middleberg [10]).

$$
\begin{aligned}
& T L=10 \log _{10} W_{\text {in }} / W_{t r} \\
& T L=10 \log 10\left\{1+\frac{1}{4}\left(m-\frac{1}{2}\right)^{2} \operatorname{Sin}^{2} k l_{c}\right\}
\end{aligned}
$$

\subsection{Proses Simulasi}

Penelitian dilakukan dengan metode simulasi, sedangkan perangkat lunak yang digunakan untuk menjalankan simulasi adalah ANSYS Harmonic Acoustics. Urutan dari proses simulasi dimulai dari engineering data, geometry, model, setup, solution, dan result .

\section{Engineering Data}

Pada engineering data dimasukkan properti fluida yang akan digunakan dalam simulasi. Pendefinisian properti fluida yang dimasukkan berdasarkan data yang diperoleh dari referensi dan ditampilkan pada Gambar 4.

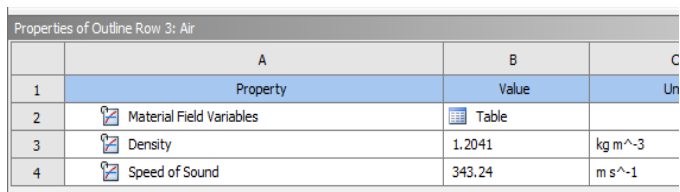

Gambar 4

Input Pada Engineering Data

\section{Geometry}

Geometri dari muffler yang akan dianalisis dimodelkan secara tiga dimensi menggunakan 
program ANSYS Design Modeler. Geometri muffler dibuat dengan menggunakan konsep dari reactive muffler dan hanya berupa single expansion chamber. Konsep reactive muffler dipilih agar dalam proses simulasi dapat lebih mudah. Diameter dan panjang dari geometri muffler disesuaikan dengan lebar fuselage pada pesawat LSU-02 agar dimensi muffler tidak terlalu besar, sehingga tidak mempengaruhi gaya hambat secara signifikan. Model geometri muffler ditampilkan pada Gambar 5 sampai Gambar 9.

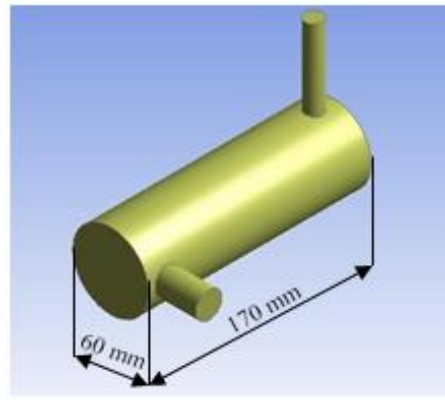

Gambar 5

Muffler Model 1

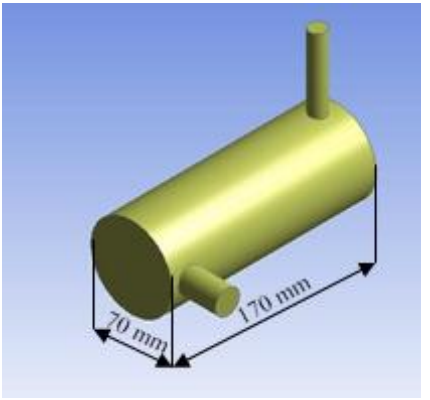

Gambar 6

Muffler Model 2

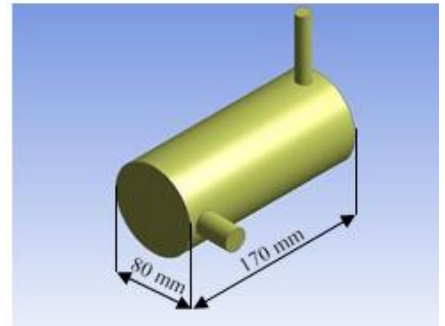

Gambar 7

Muffler Model 3

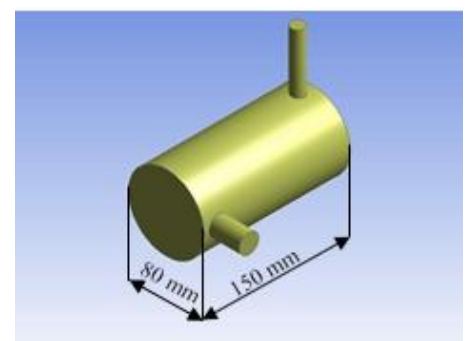

Gambar 8

Muffler Model 4

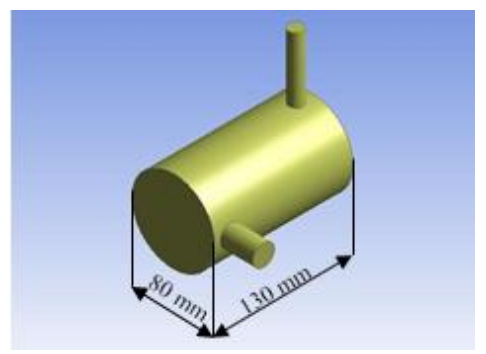

Gambar 9

Muffler Model 5

\section{Model}

Pada tahap model, dilakukan meshing menggunakan ANSYS Mesh pada geometri yang telah dibuat sebelumnya. Meshing bertujuan untuk membagi pemodelan menjadi elemen-elemen kecil agar memudahkan perangkat lunak ANSYS 
Harmonic Acoustics dalam melakukan iterasi. Hasil dari meshing ditampilkan pada Gambar 10 dengan jumlah nodal dan elemen ditampilkan pada Tabel 1.

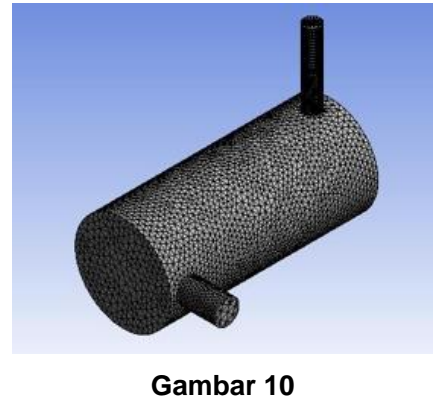

Hasil Meshing

Tabel 1.

Jumlah Nodal dan Elemen Pada Setiap Meshing

\begin{tabular}{|c|c|}
\hline Analysis Settings & $0 \mathrm{~Hz}-500 \mathrm{~Hz}$ \\
\hline Acoustics Region & All Bodies \\
\hline Mass Source & $0,005826 \mathrm{~kg} / \mathrm{m}^{3} \mathrm{~s}$ \\
\hline Radiation Boundary & Inlet dan Outlet \\
\hline Port 1 & Inlet \\
\hline Port 2 & Outlet \\
\hline
\end{tabular}

\section{Solution}

Solution merupakan tahap dilakukannya iterasi numerik yang merupakan proses dimana dilakukan perhitungan secara numerik pada setiap elemen pembagi. Perangkat lunak yang digunakan dalam iterasi numerik adalah ANSYS Harmonic Acoustics dengan solver ANSYS Mechanical APDL. Perhitungan numerik berdasarkan data properti fluida yang telah dimasukkan pada engineering data, serta sesuai dengan kondisi batas yang telah ditentukan.

\section{Result}

Pada tahap result, dapat dipilih output dari hasil simulasi yang ingin ditampilkan seperti sound pressure level, transmission loss, atau output lain sesuai dengan objek yang sedang disimulasikan.

\section{ANALISIS DAN PEMBAHASAN}

Hasil Simulasi Sound Pressure Level (SPL)

Pada Gambar 11 ditampilkan kontur warna SPL pada muffler model 1 dengan panjang $170 \mathrm{~mm}$ dan diameter $60 \mathrm{~mm}$. Dari gambar tersebut menunjukkan jika sound pressure paling tinggi berwarna merah yang berada pada inlet muffler dengan nilai $87,284 \mathrm{~dB}$. Kemudian sound pressure paling rendah berwarna biru pada bagian expansion chamber disekitar inlet muffler dengan nilai $51,936 \mathrm{~dB}$ dan sound pressure pada outlet muffler sebesar 78,244 dB.

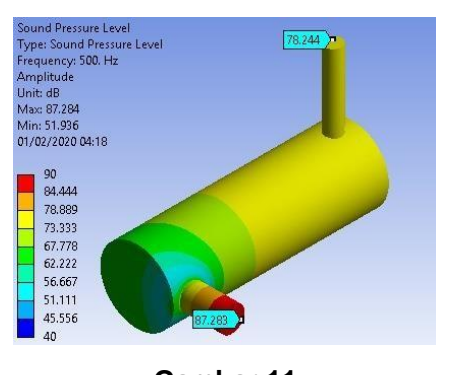

Gambar 11

Kontur Warna SPL Pada Muffler Model 1

Pada Gambar 12 ditampilkan kontur warna SPL pada muffler model 2 dengan panjang $170 \mathrm{~mm}$ dan diameter $70 \mathrm{~mm}$. Dari gambar 
tersebut menunjukkan jika sound pressure paling tinggi berwarna merah yang berada pada inlet muffler dengan nilai $87,511 \mathrm{~dB}$. Kemudian sound pressure paling rendah berwarna biru pada bagian expansion chamber disekitar inlet muffler dengan nilai 46,363 dB dan sound pressure pada outlet muffler sebesar 75,499 dB.

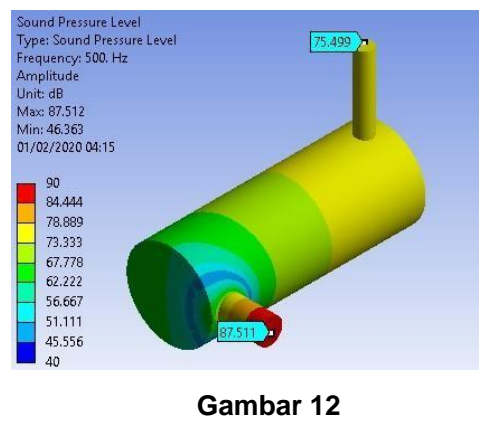

Kontur Warna SPL Pada Muffler Model 2

Pada Gambar 13 ditampilkan kontur warna SPL pada muffler model 3 dengan panjang $170 \mathrm{~mm}$ dan diameter $80 \mathrm{~mm}$. Dari gambar tersebut menunjukkan jika sound pressure paling tinggi berwarna merah yang berada pada inlet muffler dengan nilai 87,656 dB. Kemudian sound pressure paling rendah berwarna biru pada bagian expansion chamber disekitar inlet muffler dengan nilai $41,571 \mathrm{~dB}$ dan sound pressure pada outlet muffler sebesar 73,123 dB.

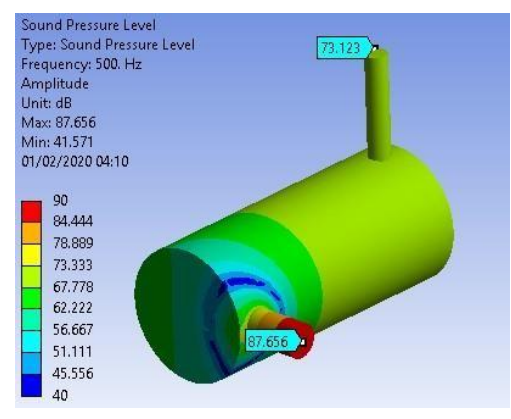

Gambar 13

Kontur Warna SPL Pada Muffler Model 3

Pada Gambar 14 ditampilkan kontur warna SPL pada muffler model 4 dengan panjang $150 \mathrm{~mm}$ dan diameter $80 \mathrm{~mm}$. Dari gambar tersebut menunjukkan jika sound pressure paling tinggi berwarna merah yang berada pada inlet muffler dengan nilai 87,365 dB. Kemudian sound pressure paling rendah berwarna biru dengan nilai 41,971 dB dan sound pressure pada outlet muffler sebesar $73,303 \mathrm{~dB}$.

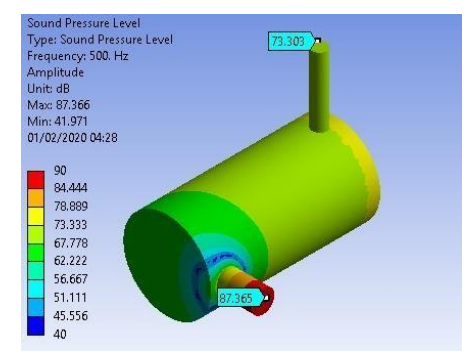

Gambar 14

Kontur Warna SPL Pada Muffler Model 4

Pada Gambar 15 ditampilkan kontur warna SPL pada muffler model 5 dengan panjang $130 \mathrm{~mm}$ dan diameter $70 \mathrm{~mm}$. Dari gambar tersebut menunjukkan jika sound pressure 
paling tingggi berwarna merah yang berada pada inlet muffler dengan nilai $87,04 \mathrm{~dB}$. Kemudian sound pressure paling rendah berwarna biru pada bagian expansion chamber disekitar inlet muffler dengan nilai 43,053 dB dan sound pressure pada outlet muffler sebesar 73,781 dB.

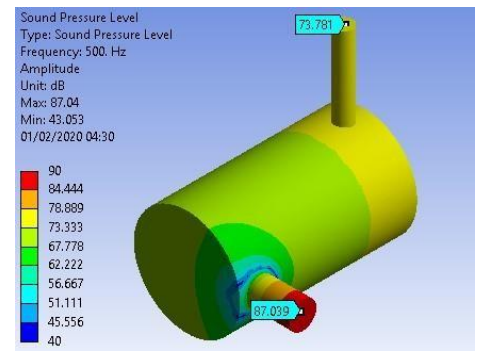

Gambar 15

Kontur Warna SPL Pada Muffler Model 5

\section{Transmission Loss Pada Perbandingan}

\section{Diameter}

Untuk mengetahui pengaruh diameter terhadap transmission loss yang dihasilkan, maka dilakukan perbandingan transmission loss pada muffler model 1, muffler model 2, dan muffler model 3.

Pada Gambar 16 ditampilkan grafik transmission loss pada perbandingan diameter muffler. Dari gambar tersebut, perbandingan grafik transmission loss juga diperlihatkan jika pada muffler model 1 (diameter $60 \mathrm{~mm}$ ) dengan grafik berwarna biru dan simbol belah ketupat, memiliki kemampuan mengurangi kebisingan sebesar 16,466 dB. Kemudian pada muffler model 2 dengan grafik berwarna merah dan simbol persegi mampu mengurangi kebisingan sebesar 19,211 dB. Terakhir pada muffler model 3 dengan grafik berwarna hijau dan simbol segitiga mampu mengurangi kebisingan sebesar 21,587 dB.

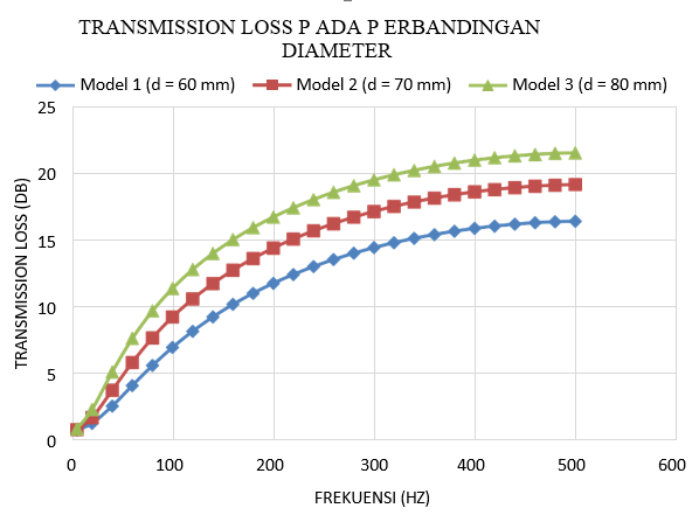

Gambar 16

Grafik Transmission Loss Pada Perbadingan Diameter

Dari nilai dan grafik pada Gambar 16 dapat dilihat jika pada muffler model 3 dengan diameter muffler $80 \mathrm{~mm}$ mampu mengurangi kebisingan lebih optimal jika dibandingkan dengan muffler dengan diameter yang lebih kecil, yaitu muffler model 1 (diameter $60 \mathrm{~mm}$ ) dan muffler model 2 (diameter $70 \mathrm{~mm}$ ). Sehingga dapat dilihat jika semakin besar diameter muffler, maka kemampuan muffler dalam mengurangi kebisingan semakin besar pula. 


\section{Transmission Loss Pada Perbandingan Panjang}

Untuk mengetahui pengaruh panjang muffler terhadap transmission loss yang dihasilkan, maka dilakukan perbandingan transmission loss pada muffler model 3, muffler model 4 , dan muffler model 5.

Pada Gambar 17 ditampilkan grafik transmission loss pada perbandingan panjang muffler.

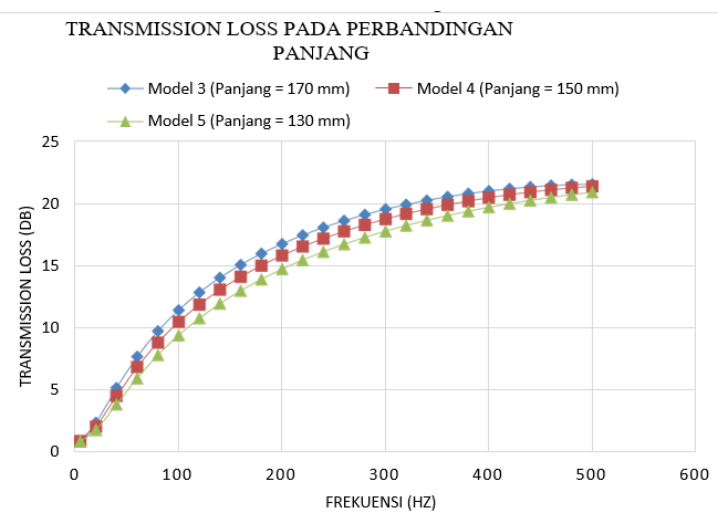

Gambar 17

Grafik Transmission Loss Pada Perbandingan Panjang

Dari gambar tersebut, perbandingan grafik transmission loss juga diperlihatkan jika pada muffler model 3 (panjang $170 \mathrm{~mm}$ ) dengan grafik berwarna biru dan simbol segitiga, memiliki kemampuan mengurangi kebisingan sebesar 21,587 dB. Kemudian pada muffler model 4 dengan grafik berwarna merah dan simbol lingkaran mampu mengurangi kebisingan sebesar 21,409 dB. Terakhir pada muffler model 5 dengan grafik berwarna hijau dan simbol persegi mampu mengurangi kebisingan sebesar 20,929 dB. Dari nilai dan grafik pada Gambar 17, dapat dilihat jika pada muffler model 3 dengan panjang muffler 170 $\mathrm{mm}$ mampu mengurangi kebisingan lebih optimal jika dibandingkan dengan muffler dengan ukuran yang lebih pendek, yaitu muffler model 4 (panjang $150 \mathrm{~mm}$ ) dan muffler model 5 (panjang $130 \mathrm{~mm}$ ). Sehingga dapat dilihat jika semakin panjang ukuran muffler, maka kemampuan muffler dalam mengurangi kebisingan semakin baik. Namun pengaruh terhadap pengurangan kebisingan tidak terlalu besar.

\section{KESIMPULAN}

Berdasarkan pada hasil dan pembahasan dari kontur warna SPL dan grafik transmission loss, maka diperoleh kesimpulan sebagai berikut:

1 Pada muffler model 3 dengan diameter $80 \mathrm{~mm}$ memberikan kontribusi yang lebih baik dalam mengurangi tingkat kebisingan sebesar 21,587 dB. Sedangkan pada muffler dengan diameter $60 \mathrm{~mm}$ hanya mampu mengurangi tingkat kebisingan sebesar $16,466 \mathrm{~dB}$. Sehingga jika semakin besar diameter muffler, maka kemampuan 
muffler dalam mengurangi kebisingan semakin besar pula.

2 Semakin panjang ukuran muffler, maka kemampuan muffler dalam mengurangi kebisingan semakin baik. Namun pengaruh terhadap pengurangan kebisingan tidak terlalu besar, karena selisih pengurangan kebisingan antara panjang muffler $170 \mathrm{~mm}(21,587 \mathrm{~dB})$ dengan panjang muffler $130 \mathrm{~mm}$ $(20,929 \mathrm{~dB})$ hanya sebesar 0,658 dB.

3 Dari lima usulan geometri yang telah disimulasikan, maka disarankan untuk menggunakan muffler model 5 dengan diameter $80 \mathrm{~mm}$ dan panjang $130 \mathrm{~mm}$ untuk dipasangkan pada mesin 3W-28i karena memiliki ukuran muffler yang tidak terlalu panjang dan mampu mengurangi tingkat bisingan sebesar $20,929 d B$.

\section{DAFTAR PUSTAKA}

[1] Bintoro, A. and S. Gunawan, Penelitian dan Kajian Teknologi Pesawat Terbang. Jakarta: Indonesia Book Project (IBP), 2013.

[2] Hidup, K.N.L., Keputusan Menteri Negara Lingkungan Hidup No. 48 Tahun 1996 Tentang: Baku Tingkat Kebisingan. Keputusan Menteri Negara Lingkungan Hidup, 1996(48).
[3] Patel, S.K.P.B., Effect of Length on Sound Reduction of the Expansion Type Muffler by Experiment and Flow Simulation.

[4] Harahap, R.O., Studi Eksperimental Reduksi Kebisingan Menggunakan Reactive Muffler pada Pesawat Tanpa Awak NVC USU. 2017.

[5] Liu, L.-y., Z.-y. Hao, and C. Liu, CFD analysis of a transfer matrix of exhaust muffler with mean flow and prediction of exhaust noise. Journal of Zhejiang University SCIENCE A, 2012. 13(9): p. 709-716.

[6] Wu, T. and G. Wan, Muffler performance studies using a direct mixed-body boundary element method and a three-point method for evaluating transmission loss. 1996.

[7] Kore, S., A. Aman, and E. Direbsa, Performance evaluation of a reactive muffler using CFD. Zede Journal, 2011. 28: p. 83-89.

[8] Ji, Z., Acoustic attenuation performance analysis of multichamber reactive silencers. Journal of sound and vibration, 2005. 283(1-2): p. $459-466$.

[9] Milad, E.M. and M. Jolgaf, Acoustic Analysis of a Perforated-pipe Muffler Using ANSYS. 
Infomatek Volume 22 Nomor 2 Desember 2020 : 51 - 60

[10] Middelberg, J., et al. Computational fluid dynamics analysis of the acoustic expansion chamber mufflers. in performance of various simple Proceedings of Acoustics. 2004. 